\title{
Analysis on the Professional Development of New Professional Farmers under the Background of Rural Revitalization Strategy
}

\author{
Jun Wang \\ School of Marxism, \\ Xijing University, \\ Xi'an, Shaanxi 710123, China \\ wangjun2891@163.com
}

\begin{abstract}
New-type professional farmers are the main force to realize agricultural modernization in China,cultivation of newtype professional farmers are the important part of the structural reform of agricultural supply side. With the implementation of the rural revitalization strategy, completing the building of a moderately prosperous society in all respects and construction of beautiful countryside, the trend of promoting farmers' professionalization and specialization has been clear, and it's inevitable that farmers with traditional status will be transformed into professional farmers. Based on the shortcoming of the weakening of the main body of agricultural production, we draw on the policy choices of foreign farmers for professionalization and specialization development, analyze the internal mechanism and external conditions of the professional development of new professional farmers, and then construct a new professional farmer development mechanism from identity to occupation.
\end{abstract}

Keywords-Rural Revitalization; New Professional Farmers; Specialization; Cultivation Mechanism

\section{INTRODUCTION}

Implementation of the rural revitalization strategy, giving priority to the development of agriculture and rural areas, and promoting the structural reform of the supply side of agriculture, are essentially to realize the modernization of agriculture and rural areas. Whether it is to cultivate the new trend of agricultural industrialization development, or to build and promote the new momentum of the prosperity of production industry, it is inseparable from the main body of modern agricultural industry system, namely, the new professional farmers. As a national strategy, the cultivation of new-type professional farmers have been carried out in an allround way. How to ensure that new-type professional farmers become the main body of modern agricultural production of the new generation, which is of great practical significance.

\section{Necessity of Professional DeVelopment of NeW PROFESSIONAL FARMERS}

On the occasion of the 40th anniversary of reform and opening up, the degree of modernization of China's agricultural development has steadily improved, however, compared with other fields such as industry, science and technology, communications and so on, it Still belong to agricultural development weak board. In the process of completing the building of a moderately prosperous society in all respects and realizing the goal of becoming a great modern country in an all-round way, the weakening of the main body of agricultural production bears the brunt. The new type of professional peasants are the demographic factor that force the integration of urban and rural development, promote the structural reform of the agricultural supply side, deepen the concept of green agriculture into the countryside, and accelerate the process of agricultural industrialization. [1] Speeding up the professional development of the new type of professional peasants and solving the shortage of talents in the process of rural economic development,which are inevitable move for rural revitalization in the new era.

\section{A. New professional farmers force the development of urban- rural integration}

With the sustained efforts of supporting policies such as the revitalization of agricultural industry, the protection of farmers' rights and interests, and the governance of rural environment, a large number of young college students and young migrant workers are attracted to return home for business and employment, great "narrowing" the regional distance between urban and rural areas, and "blurring" the spatial differences between urban and rural areas, impelling the elimination of system and mechanisms barriers to the integration of urban and rural development. Promoting rural revitalization, adhering to the priority development of rural areas and agriculture, are inseparable from the cultivation of new professional farmers. Compared with the traditional peasants, the new type of professional peasants are branded with the era of reform and opening up and agricultural modernization, and introduced modern professional elements such as new technology, new machinery, new energy and new communication in modern agricultural. The new-type professional peasants keep pace with the changes of urbanized population, in terms of education level, knowledge structure, ideology, working ability and economic income. The gap between them and urban residents in terms of public services such as pension, education, medical treatment, transportation, water supply and power supply have gradually narrowed, and 
the dual economic structure of urban and rural areas have gradually shrunk.

\section{B. New professional farmers promote the structural reform of agricultural supply side}

The gap restricting the development of modern agriculture in China comes from the characteristics of traditional agriculture itself. The prominent problems such as "one family" small-scale operation, extensive management, lowlevel organization and scarce social services have not been effectively solved. Deepening the structural reform of agricultural supply side, breaking the barriers of spatial and regional division between traditional agriculture and modern agriculture, innovating the mode of agricultural production, management and organization, realizing the integration of primary, secondary and tertiary industries, improving the quality and efficiency of agricultural products supply, and building a new agricultural management system are the objective requirements of modern agricultural development. The new types of professional peasants, representing the development potential of the new era, are mainly the backbone of some professional farmers and agro-processing entrepreneurs. Through these specialized peasant teams with modern management concepts, we can build new agricultural business entities, tap rural human tourism resources, give full play to the green ecological value of the countryside, and realize the integration of agricultural and industrial development.

\section{New professional farmers deepen the implantation of green agriculture idea into rural areas}

The concept of green agriculture development is the embodiment of advanced productive forces in the sustainable development of agriculture.[2] Breaking the uncoordinated and unbalanced status of internal circulation and external circulation of agricultural production,that is the premise basis for the development of agricultural. It is a complex systematic project, to meet the needs of contemporary people for highquality agricultural products, to protect the ecological resources of rural survival, to promote the adjustment of agricultural production relations, to build sustainable advanced productive forces. From the perspective of economic factors, we should not only deal with the internal economic problems of agricultural production such as production, technology, resources, environment, ecology and population, but also deal with the external social and economic factors such as market, distribution, consumption, life and society. From the perspective of social factors, we should not only deal with the regulation relations within the system of "policies, laws, regulations, management and concepts" in agricultural society, but also deal with the regulation relations outside the system of integration of primary, secondary and tertiary industries. To adjust agricultural production relations, promote the release of advanced agricultural productivity,promote sustainable development of agriculture, we need to change our ideas,deeply plant the concept of green agriculture in the fertile soil of the countryside. New professional farmers in the new era,yearn for advanced agricultural production technology and modern agricultural management concepts, face up to and attach importance to rural ecological environment protection, familiarize themselves with ecological protection and green development policies.Actively explore new momentum and direction of modern agricultural development, and become an important force to deepen the concept of green agriculture implanted into the countryside.

\section{New professional farmers accelerate the process of agricultural industrialization}

The new professional farmers, with the mastery and input of modern elements,such as industrialization, informationization and scientificalization, break the low-level repetitive production of traditional agriculture, promote the application of modern science and technology and scientific management.In agricultural production practice, promote the development of agricultural industrialization,realize the modernization of agriculture, which by the combination and transformation of agriculture and industrialization. At present, the concept of precision agriculture have been widely docked with the new scientific and technological circles and the society. Through the application of modern industrial production elements in agricultural production, such as agricultural mechanization, industrialization, informationization and intellectualization, only modern newtype professional farmers as representatives of advanced productive forces, who can adapt to the high-tech and refined working requirements of modern agricultural production. In the new era, the country promotes the strategy of rural revitalization, new-type professional farmers have a high level in cultural quality, moral accomplishment, management concept, management level, technical ability, legal consciousness, innovative spirit and entrepreneurial potential. They can contribute to creating a new countryside with prosperity, harmony, beauty and happiness,as other professions do.

\section{POLICY CHOICE OF FOREIGN FARMERS' PROFESSIONAL DEVELOPMENT}

\section{A. The development course of foreign farmers' professionalization}

The development of foreign farmers' professionalization is the process of the rapid rise of industry,to promote agriculture and cities to drive rural development. [3]Although there are different paths of farmers' professionalization in western developed countries, their common characteristics, are that with the development of market economy, the improvement of labor productivity, the clear division of specialization, the gradual emergence of classified occupations, and the formation of professional farmers engaged in agricultural industry. The new type of professional farmers have deep market participation, high degree of freedom of choice, advanced agricultural production technology and rich cultural knowledge, adapt to the large-scale agricultural industrialization production in the new era, pursue the maximization of wealth and agricultural production benefits , and conform to the trend of knowledge economy and agricultural ecology development. Professional peasants have the characteristics of professionalism, dynamism, skill and market. 


\section{B. Policy choice of farmers' professionalization in Britain, America and Japan}

Farmers' professionalization in Britain have its own characteristics, it promotes the cultivation and development of rural market,through industrialization-driven industrial chain extension and Urbanization-Driven population migration. In this process, it combines agricultural industrialization with farmers' professionalization,to realize the transformation of farmers' professional identity. The road of farmers' professionalization in Britain,which have formed a government-led, professional associations or cooperative organizations as the carrier, linking decentralized farmers with the market,and then, through the farmers' vocational education, agricultural science and technology promotion, agricultural development and counseling centers, establish long-term consulting relationships with farmers,to improve the professional level of professional farmers. The professionalization of farmers in the United States, whcih are based on the characteristics of rich land resources and small rural population. The large-scale operation, mechanized operation, scientific and technological support, and marketoriented guidance are used to achieve high professionalization of farmers. In addition, the implementation of land development and protection policy, family farm system and farmers' vocational education and training system by the U.S. government have created a good policy, system soft environment and objective conditions for the formation and development of professional farmers. Through the development of industry, Japan encourages scattered smallscale farmers to go out of the country to work, and through the government to regulate the transfer of rural surplus labor, to achieve rural land scale operations. Although Japan's land transfer rate is slow and its concentration is lower than that of European and American countries, administrative legislation is taken as a guarantee, and a series of measures such as land reform, establishment of agricultural associations, and agricultural technology improvement are adopted. At the same time, of improving agricultural productivity, the state plans and implements peasant education and training at different levels, in order to realize agricultural production and related peasant professionalization.

\section{THE INTERNAL MECHANISM AND EXTERNAL CONDITIONS OF THE PROFESSIONAL DEVELOPMENT OF NEW PROFESSIONAL FARMERS}

China's new type of professional farmers can become a new occupation with the characteristics of socialization, specialization and standardization. In the final analysis, they have the internal and external generating conditions. The largescale planters, family farmers and organizers of rural professional economic cooperation organizations, who are currently engaged in agricultural production and management are the main forces of new professional farmers. The second and third generations of farmers are the quasi-vital forces for the professional development of new-type professional peasants. They will take the new-type professional peasants as the most suitable career choice from a wide variety of dazzling occupations.

\section{A. The internal mechanism of professional development of new professional farmers}

In the new era ,farmers and their descendants can take agricultural production and related industries as the direction of professional development, which are the internal mechanism of the formation of new professional farmers.[4] Firstly, in terms of professional interests, professional farmers have an inherent influence on the second and third generations of farmers, in their life, the first occupation they come into contact with is the farmer occupation, their parents are engaged in. When they may not have time to understand the meaning of professional farmers, professional psychological identity will gradually emerge and build up with the sense of interest. Starting from their professional interests, they will take the new professional peasants as their career goals and devote themselves wholeheartedly. Secondly, in terms of value orientation, growing up in rural areas makes farmers and their descendants familiar with the agricultural production process and environment, and have unique advantages in choosing new types of professional farmers. This advantage will become a subtle hint, so that they have a preference for the occupation of farmers. Compared with other unfamiliar occupations, it is most likely and suitable to yearn for a career familiar to one. Thirdly, in terms of vocational ability, because living in rural areas, farmers and their descendants have the advantages of professional familiarity and professional experience, this advantage will become the prerequisite and necessary condition to be able to compete for the new type of professional farmers. [5] Workers engaged in agricultural production for a long time will inevitably be able to master professional agricultural knowledge, skills and production experience, and be promoted and strengthened in long-term production practice, laying a good foundation for them to be competent for new types of professional farmers.

\section{B. The external conditions for the professional development of new professional farmers}

At present, the new occupational peasant cultivation plan is gradually unfolding, the strategic position of agricultural and rural priority development is outstanding, the public infrastructure is continuously improved and the level of social public service guarantee is continuously improved, multidimensional factors of production conditions, environmental impacts, economic benefits and educational means have been comprehensively improved, it have laid the objective foundation and conditions for the professional development of new professional farmers. Firstly, the gradual improvement of the new professional peasant cultivation system, which is the basis for the professionalization of new professional peasants. Secondly, the state's support for agriculture has been increasing, creating favorable conditions for farmers engaged in agricultural production. Thirdly, we should encourage migrant workers to return home and start businesses, so as to open up a new path for the cultivation of new professional farmers. Fourthly, the reform of the household registration system, which have eliminated institutional barriers to peasant citizenization. The issuance of residence permits has promoted the speed of agricultural transfer population to settle down. At the same time, the state have introduced a series of corresponding policies and 
measures, which provide an effective means to solve the practical problems concerning education, employment, medical treatment, old-age care, housing security and the three rights in rural areas, which are most concerned by the majority of farmers. Fifthly, the construction of beautiful countryside has improved the ecological livable living environment of farmers.

\section{FROM IDENTITY TO OCCUPATION: CONSTRUCTION OF Cultivation MECHANiSM FOR PROFESSIONAL DEVELOPMENT OF NEW PROFESSIONAL FARMERS}

\section{A. Career guidance mechanism}

Some domestic scholars found in rural surveys that farmers are willing to receive training, but there is a gap in the number of farmers and volunteers who actually go to training. First, farmers are influenced by traditional habitual thinking, they have insufficient understanding of the importance of farmers' professional education and training. Second, they are restricted by economic conditions and are unwilling to bear training costs. This idea is prevalent in rural areas. [6] The fixed production mode have been normalized and the rules are difficult to break. Therefore, in order to make the development of agricultural industrialization take root in the new era, we must vigorously publicize the concept of modern agricultural production, the new requirements for modern professional farmers are promoted in the form of national strategies, the whole society publicizes and guides farmers to participate in the study of professional modernization, let the new professional farmers cultivate into the mind.

\section{B. Career support mechanism}

The cultivation of new-type professional peasants is a long-term work with professionalism, technology, science and sustainability. From secondary agricultural vocational education to higher agricultural vocational education and training, and then to agricultural production on-the-job continuing education, it is the inevitable requirement of modern agricultural production for professional peasants. It is also the inevitable trend of China's agricultural mechanization, science and technology, and information development in the future, it is a lifelong agricultural professional education that must be carried out for new professional farmers. According to the relevant statistical investigation and analysis, there are fewer farmer education institutes in agricultural colleges and universities in China at present, and there is a big gap, in order to prevent the emergence of faults in new professional farmers, governments at all levels should take measures to change the current absence of vocational education and training for farmers as soon as possible. In view of the fact that new types of vocational farmers receive re-education, they should be distinguished from students in agricultural colleges and universities. It is recommended that the state set up a peasant education college in higher-level agricultural colleges at different levels in the country to carry out different levels of advanced training and education, such as crop planting, agricultural mechanization, and agricultural informationization. It is not only suitable for the education of rural professional farmers, but also suitable for the learning needs of the new generation of rural professional farmers in the future.

\section{CONCLUSION}

At present, the cultivation of new-type professional peasants in our country has been carried out in an all-round way, guiding peasants to make career choices based on their own professional development needs, actively integrating into the process of agricultural modernization requirements for peasants' vocational education. The effective way to change the situation of passive acceptance is to provide necessary vocational guidance to peasants, so that they can change from passive training to active training. The cultivation of new-type professional farmers is a systematic project involving the transformation of rural economic development. It needs to form a community of interest links, which is led by the government, driven by the market, participated by enterprises, and linked by farmers, agricultural enterprises and agricultura colleges. [7] Give play to the government's policy, funds, and system support, and optimize the allocation of resources and the flow of agricultural elements by the market, encouraging agricultural-related enterprises to participate in the primary, secondary and tertiary industries and to agglomerate the cluster effect of agricultural industry. Promote the mutual growth and benefit sharing of farmers, agricultural enterprises and agricultural colleges and universities, and build a sustainable development mechanism for the cultivation of new professional farmers.

\section{REFERENCES}

[1] Zhao Chunjiang, Zhao Yingxia. On the Cultivation and Innovation of New Farmers' Professional Ability in the Process of Rural Revitalization[J].Research on Continuing Education.2018(10):27-34.

[2] Sun Tianwei, Dong Xingyong. Preliminary Study on Agricultural Technology Extension under the Concept of Green Agriculture[J].New agriculture.2018(17):54-56.

[3] Zhang Yijun, Qin Yuanfang. Summary of Research on Cultivation of New Professional Farmers at Home and Abroad[J].Contemporary Continuing Education.2018,36(05):15-19.

[4] Fan Li Jun. On the Optimizing of Farmers' Vocational Education System from the Perspective of Rural Revitalization[J].Anhui Agricultural Science Bulletin.2018,24(22):12-13+17.

[5] Qiu Limin, Zhong Yuhong and Ma Hao. Vocational Education Action Strategies for Cultivating New Professional Farmers from the Perspective of "Farmer Shortage"[J].Vocational and Technical Education in China. 2018(26):26-31+35.

[6] Xiao Jian. Evolution of China's Resident Income Gap since Reform and Opening-up: Based on 1978-2017 Data[J].Yinshan Academic Journal. 2018,31(05):19-29.

[7] Liu Fengyue, Chen Ke. Research on the Cultivation of New Professional Farmers from the Perspective of Stakeholders[J].Vocational Education Forum.2018(05):89-93. 